\title{
Effect of Implementing Fluid Therapy Protocol on Pregnant and Postpartum Women Outcomes Who At Risk For Developing Acute Kidney Injury
}

\author{
Amal Abd El-nasser Mohamed ${ }^{1}$, Zein Elabedeen Zareh Hassan ${ }^{2}$, Olft Abdelgny Elshafhy ${ }^{3} \&$ Mogedda $^{4}$ \\ Mohamed Mehony ${ }^{4}$. \\ 1-Nursing specialist, Women Health Hospital, Assiut University, Assiut, Egypt. \\ 2-Professor, Anesthesia and Intensive Care Department, Faculty of medicine, Assiut University, Assiut, Egypt. \\ 3-Assistant professor, Critical care nursing Department, Faculty of Nursing, Assiut University, Assiut, Egypt. \\ 4-Assistant professor, Critical care nursing Department, Faculty of Nursing, Assiut University, Assiut, Egypt.
}

\begin{abstract}
Acute kidney injury (AKI) is a common and serious problem affecting millions and causing death and disability for many people. Aim of the study was to evaluate the effect of implementing fluid therapy protocol for pregnant and postpartum women outcomes who at risk for developing acute kidney injury. Patients and Methods: Quasi experimental research design was used to conduct this study; the study was carried out in Obstetric ICU at Assiut University Hospital. The study sample consisted of intervention group (15 patients) who received fluid therapy protocol and control group (15 patients) who received only the routine hospital care, the study was conducted in 6 months. Tools: first tool "Renal impairment assessment sheet", second tool "Protocol of fluid flow chart ", third tool "Patients' outcomes evaluation sheet". Results: No patients in the intervention group developed acute kidney injury but $60 \%$ of control group developed AKI with a statistical significant difference between intervention and control groups in relation to developing AKI $(\mathrm{P}=0.001)$. Conclusion: Implementing fluid therapy protocol was significantly effective in preventing developing AKI among at risk pregnant and postpartum women. Recommendations: Emphasize on the importance of accurate monitoring of urine output and CVP in obstetric patients who at risk for developing AKI in detection and preventing any problem or deterioration.
\end{abstract}

\section{Keywords: Fluid Therapy Protocol \& Acute Kidney Injury.}

\section{Introduction}

Acute kidney injury is considered as significant challenges in the clinical field .An awareness of the historical background to AKI is required in understanding the challenges in the management of AKI (John, 2012).

Acute kidney injury, previously known as acute renal failure, encompasses a wide range of injury to the kidneys, not just kidney failure. The definition of acute kidney injury has changed in the previous years, and recognition is now mostly based on monitoring Creatinine levels, with or without urine output (Praught, 2005).

There are deep changes in renal function in normal pregnancy, which lead to marked alterations from the non pregnant physiologic norms (Baylis et al., 2007 \& Steddon et al., 2006). Understanding the physiologic changes and disorders that occur in women with renal disease in pregnancy makes the basis of appropriate management of these unusual disorders Lindheimer et al., (2010). Up to $50 \%$ of AKI patients are thought to develop in the hospital. Approximately 5\% of hospital patients admitted to obstetric units will have their admission complicated by the development of AKI (Cheung et al., 2008). At present there is no cure for AKI and the key principles of its management include early recognition, hemodynamic optimization, correction of hypovolemia, avoidance of Nephrotoxic medications, and treatment of the underlying cause. Data show that the type and volume of fluid therapy can affect renal function and that further guidance is required (Bouchard, 2009).

Acute kidney injury (AKI) is an important complication during pregnancy. There is a marked decline in the incidence of pregnancy related acute kidney injury (PRAKI) over the past 50 years in industrialized countries as a result of improved antenatal care and obstetric practices (Rani \& Narayen, 2002).

In all healthcare settings, Nurses play a pivotal role in improving outcomes, especially by identifying risk factors and helping to prevent AKI. The extent to which nurses can influence the management of AKI will depend on their role and place of work. Generally, nurses because of their nearness to patients are the first to observe and be aware of a deterioration of renal function. Their knowledge of renal functions and pathophysiology, and skilled proficiency in patient assessment, monitoring and interpreting data as well as understanding of current evidence based interventions play an important role in preventing complications and improving the outcomes and well-being of individuals of AKI (Remond et al., $2004 \&$ Yaklin, 2011). 
It was noticed that one of the causes of admission to intensive care unit was AKI which may developed to chronic renal failure and may be cause of death. It had increased incidence in pregnant and postpartum women due to renal effects of pregnancy, and rate of these patients was increased in the previous years, The rate of admission of women with renal impairment in (2015-2016 ) at Assiut university hospital at obstetric ICU was about 76 patients, 14 patients from these patients developed chronic renal failure and became on regular dialysis and 10 patients died, the management for this disease is very important, therefore, this study was carried out in applying standardized nursing care by using fluid therapy protocol for pregnant and post partum women who at risk for developing acute kidney injury.

\section{The Aim of the Study}

The aim of this study was to evaluate the effect of implementing fluid therapy protocol on pregnant and postpartum women outcomes who at risk for developing acute kidney injury.

\section{Operational definitions}

Fluid therapy protocol

Is a protocol used saline $0.9 \%$ as maintenance fluid according to CVP and urine output for pregnant and postpartum women who at risk for developing AKI.

Pregnant and postpartum women outcomes

It includes evaluation of pregnant and post partum women who at risk for developing AKI for days of staying in ICU, if the patient had hemodialysis sessions, if there were complications and mortality rate.

\section{Research hypothesis}

There is a relationship between outcomes of pregnant and postpartum women with renal impairment and fluid therapy protocol.

\section{Subjects \& Methods}

\section{Research design}

Quasi experimental research design was used to conduct this study.

Setting of the study:

This study was carried out in obstetric Intensive Care Unit at Women Health Hospital at Assiut University from $20 / 10 / 2016$ to $20 / 4 / 2017$.

\section{Sampling}

Purposive sample was taken. The study sample consisted of all pregnant and post partum women with renal impairment who at risk for developing AKI admitted to the obstetric intensive care unit within 6 months, (30 patients) classified to two equal groups (15 patients as intervention group who received fluid therapy protocol and 15 patients as control group who received only the routine hospital care).

\section{Exclusion criteria}

Patients had previous history of medical disease in the kidneys, Diabetic patients had renal impairment, and Patients had suprarenal (adrenal gland) disorders. Study tools

Three tools used in this study were developed by the researcher based on reviewing of the relevant literatures Davenport \& Stevens, (2008), Navadiya et al, (2016), Anthony \& Michael, (2009), Westacott, (2009) and South Australian perinatal practice guidelines work group (2001).

\section{Tool one: - Renal impairment assessment sheet}

This tool was developed by the researcher after reviewing of literatures (Davenport \& Stevens, 2008) , Navadiya et al., (2016) \& Anthony \& Michael , (2009), used to assess patient condition, and divided into five parts:-

Part I: Personal characteristics and medical data Personal characteristics data included patient's code number, age, sex and marital status. Medical data included parity, gestational age, type of delivery, past history, present illness, date of admission, date of discharge and length of stay in Obstetric ICU.

Part II: Assessment of hemodynamic status:

This part was used to assess hemodynamic status that included temperature, respiratory rate, pulse, blood pressure (BP) taken from bed side monitor, monitoring of urine output and central venous pressure (CVP).

Part III: Physical examination that consisted of General appearance which included assessment for pallor, jaundice, cyanosis, edema (site of edema, type of edema, degree of edema by using (scale+1to+4)

Brodovicz, (2009), and assessment for hydration

Chest examination which included auscultation for any abnormalities as (wheezing, Bronchospasm, Crepitation) and chest $\mathrm{x}$-ray.

\section{Part IV: Laboratory investigations}

Laboratory investigations that included complete blood picture, coagulation profile, serum electrolytes as $(\mathrm{Na}, \mathrm{K}, \mathrm{Ca}, \mathrm{Mg})$, kidney functions which include urea , Creatinine, liver functions which include AST,ALT, albumin,total protein ,total bilirubin, direct bilirubin and arterial blood gases and acid base status. Part V: Fluid balance record

It included fluid intake involving oral, IV fluids and hidden fluids such as (IV antibiotics additives, liquid medications, frozen treats, ice chips) and losses involving urine output, nasogastric secretions, wound drainage and diarrhea.

Tool two: protocol of fluid flow chart

This tool was adapted from the following literature Westacott, (2009) \& South Australian perinatal 
practice guidelines work group, (2001) who used Hartman solution as fluid therapy in this protocol and due to unavailability of this solution in our hospitals in Egypt, it was replaced by saline $0.9 \%$ which is nearly similar in its components to Hartman solution and there are studies approved its benefits than Hartman solution.

Tool three: Patients' outcomes evaluation sheet It included evaluation of

- Days of staying in ICU.

- If the patient had hemodialysis sessions.

- If there were complications such as pulmonary edema, developing chronic renal failure...others and mortality rate.

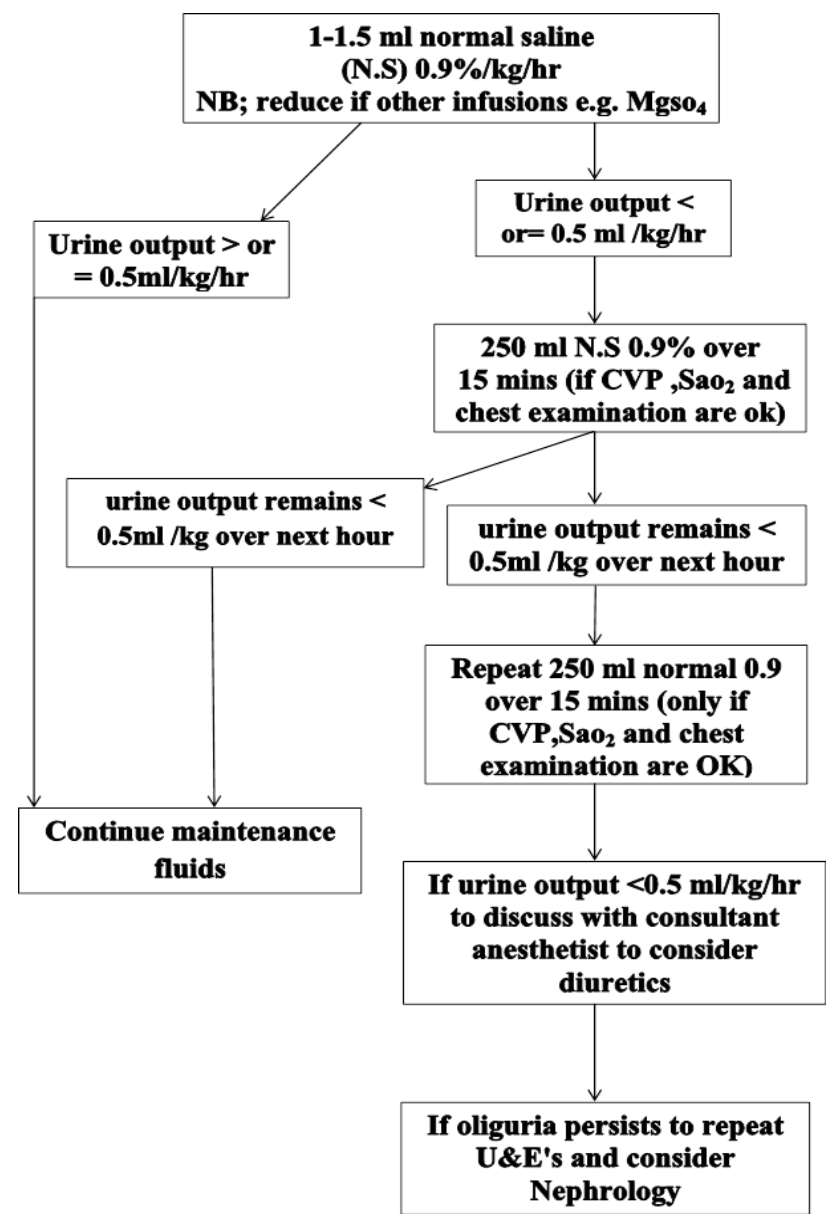

Protocol of fluid flow chart

\section{Method}

The study was conducted throughout four main phases, which were preparatory phase, assessment phase, implementation phase and evaluation phase:

Preparatory phase

- Seeking official and non official permission to conduct the study were obtained by the researcher from the head of the obstetric intensive care unit after explanation of aim and nature of the study.

- Construction for data collection tools after extensive literature of review.

- Content validity: the tools were tested for content related validity by jury of 5 specialists in the field of critical care nursing and critical care medicine from Assiut University then the tools were designed in their final format and tested for reliability using internal consistency for all of the tools which was measured using cronbach`s test. The tools proved to be reliable (0.837).

- A pilot study was conducted on 4 patients to test the feasibility and applicability of the tools and the analysis of the pilot study revealed that minimal modifications are required, these necessary modifications were done and the pilot study subjects were excluded from the actual study.

Ethical considerations

- Research proposal was approved from Ethical Committee in the faculty of nursing.

- There was no risk for study subject during application of the study.

- The study followed common ethical principles in clinical research.

- Oral consent was obtained from patients that participated in the study, after explaining the nature and purpose of the study.

- Patient was assured that the data of this research was not be reused without second permission.

- Confidentiality and anonymity was assured.

- Patients had the right to refuse to participate or withdraw from the study without any rational at any time.

Data collection

- Data were collected in six months from 20/10/2016 to $20 / 4 / 2017$.

- The data were collected from the first day of admission after stabilization of the patient's condition and until the patient improved or discharged from the Obstetric ICU, every day and every shift and every hour then the data were recorded in the developed tools.

- The researcher assigned study sample (30 patients) to two equal groups (Control group, intervention group).

- For the control group: The researcher assessed patients who were receiving the routine hospital care.

- For intervention group: The researcher assessed patients then applying standardized nursing care by using fluid therapy with normal saline $0.9 \%$ and maintaining daily body requirement of water.

Assessment phase for control and intervention group 
- During this phase the researcher assessed each patient from the first day of admission and record patient's personal characteristics and clinical data before any data collection by taking this information from her sheet using tool 1 Part 1.

- The researcher assessed homodynamic status of patient hourly by using tool 1part 2, also physical examination was done twice daily by using tool 1 part 3. Laboratory investigations included complete blood picture, coagulation profile, serum electrolytes, kidney functions, liver functions and arterial blood gases and acid base status were monitored daily by using tool 1part 4 .

- The researcher assessed fluid intake involving oral, IV fluids and hidden fluids such as (IV antibiotics additives, liquid medications, frozen treats, ice chips) and losses involving urine output, nasogastric secretions, wound drainage and diarrhoea hourly by using tool 1 part 5 .

Implementation phase for intervention group

- The researcher administered and restricted fluids by using protocol of fluid flow chart guided by CVP and urine output hourly and according to the patient condition as in case of dehydration and hypovolemia due to any cause such as (blood loss, severe vomiting), rehydration by fluids including colloid and crystalloid until reaching by CVP to normal range.

- Bolus volume expansion is indicated for correction of circulatory losses, e.g. before regional blockade, vasodilator treatment, wound drain or nasogastric loss.

- Specific blood product deficits should be corrected with fluid type based on measured losses.

- In cases of oliguria use boluses of $250 \mathrm{~mL}$ over 3060 minutes. This may be repeated up to a maximum of 1,000-1,500 $\mathrm{mL}$ per 24 hours, depending on clinical signs.

- If urine output< $0.5 \mathrm{ml} / \mathrm{kg} / \mathrm{hour}, \mathrm{CVP}$ measured and assessment of fluid balance and reached by CVP to normal range by administration of fluids according to the patient condition (in the case of blood loss; replacement of volume depletion by blood transfusion until CVP be in the normal range) then continued on maintenance fluid according to the protocol of fluid flow chart with accurate measuring of CVP and urine output hourly.

\section{Maintenance fluid}

- In general, use maintenance of crystalloid supplemented with specific fluid products.

- Administer all fluids via a volumetric infusion pump.

- Sodium chloride $0.9 \%$ is the fluid of choice.
- Avoid solutions with high water concentration, e.g. dextrose 4 or $5 \%$.

\section{Rate of infusion}

- Determined by potential for fluid overload and possible requirement for other fluids, e.g. blood products.

- 1 - $1.5 \mathrm{~mL} / \mathrm{kg} / \mathrm{hr}$ provided; there are no requirement for other fluid and no evidence of fluid overload.

- $0.5-1.0 \mathrm{~mL} / \mathrm{kg} / \mathrm{hr}$ if likely to require other fluids, e.g. blood, albumin, other colloid.

- $0-0.5 \mathrm{~mL} / \mathrm{kg} / \mathrm{hr}$ if fluid overloaded or there is left ventricular dysfunction.

- If after hour ,urine output $<0.5 \mathrm{ml} / \mathrm{kg} / \mathrm{hr}$, followed up fluid flow chart, if no response inform experienced anesthetist to consider the dose of diuretics and send blood sample for the lab to check kidney functions .

- If anuria (no urine output over 1 hour after using diuretics) request review by experienced anesthetist to consider nephrology.

- Performing daily checking for serum urea, serum Creatinine and serum electrolytes and comparing the results with the baseline of the patient.

- Providing adequate hydration by maintaining normal body requirement of water per day in the form of (30-35ml/kg/day) and divided into $24 \mathrm{hrs}$ and administered hourly.

- Undertaking regular and fluid balance monitoring, recognizing when urine output fall below 0.5 $\mathrm{ml} / \mathrm{kg} / \mathrm{hr}$.

Evaluation phase

- This phase was done to evaluate effect of applying fluid therapy protocol on preventing developing acute kidney injury.

- Each patient was evaluated 3times from admission till discharge (on admission, on mid period of ICU stay and on discharge) by using tool 1 and tool 3 .

\section{Statistical analysis}

- Data were computerized and analyzed by computer programmed SPSS (ver.16).Data were presented by using descriptive statistics in the form of frequencies and percentages or means \pm standard deviations for qualitative data. Quantitative data were compared using Independent samples t- test for comparisons among two groups. Qualitative variables were compared using chi-square test to determine significance.

- The critical value of the tests "P" was considered statistically significant when $\mathrm{P}$ less than 0.05 . 


\section{Results}

Table (1): Comparison between intervention and control groups in relation to personal characteristics and medical data of, $(\mathrm{N}=30)$.

\begin{tabular}{|c|c|c|c|c|c|}
\hline \multirow[t]{2}{*}{ Personal characteristics } & \multirow{2}{*}{\multicolumn{2}{|c|}{$\begin{array}{c}\text { Intervention } \\
(n=15)\end{array}$}} & \multicolumn{2}{|c|}{$\begin{array}{c}\text { Control } \\
(n=15)\end{array}$} & \multirow[t]{2}{*}{ P-value } \\
\hline & & & \multicolumn{2}{|c|}{ Mean \pm SD } & \\
\hline Age (years) & \multicolumn{2}{|c|}{$26.07 \pm 5.20$} & \multicolumn{2}{|c|}{$28.47 \pm 5.18$} & 0.244 \\
\hline Gestational age (weeks) & \multicolumn{2}{|c|}{$35.47 \pm 4.91$} & \multicolumn{2}{|c|}{$34.87 \pm 4.91$} & 0.738 \\
\hline Parity & \multicolumn{2}{|c|}{$1.73 \pm 1.67$} & \multicolumn{2}{|c|}{$2.93 \pm 2.63$} & 0.228 \\
\hline \multirow[t]{2}{*}{ Medical data } & \multicolumn{2}{|c|}{$\begin{array}{l}\text { Intervention } \\
\quad(n=15)\end{array}$} & \multicolumn{2}{|c|}{$\begin{array}{c}\text { Control } \\
(n=15)\end{array}$} & \multirow[t]{2}{*}{ P-value } \\
\hline & No. & $\%$ & No & $\%$ & \\
\hline \multicolumn{5}{|l|}{ Type of delivery } & \multirow{3}{*}{0.058} \\
\hline Normal vaginal delivery & 3 & 20.0 & 8 & 53.3 & \\
\hline Cesarean section & 12 & 80.0 & 7 & 46.7 & \\
\hline \multicolumn{6}{|l|}{ Past history } \\
\hline No & 14 & 93.3 & 13 & 86.7 & 0.543 \\
\hline Asthmatic & 1 & 6.7 & 1 & 6.7 & 1.000 \\
\hline Rheumatic heart disease & 0 & 0.0 & 1 & 6.7 & 0.309 \\
\hline \multicolumn{6}{|l|}{ Present illness } \\
\hline Pregnancy induced hypertension(PIH) & 9 & 60.0 & 5 & 33.3 & 0.143 \\
\hline Hemorrhage with its types & 6 & 40.0 & 5 & 33.3 & 0.705 \\
\hline Cardiac disease & 0 & 0.0 & 2 & 13.3 & 0.483 \\
\hline Acute fatty liver & 1 & 6.7 & 2 & 13.3 & 0.543 \\
\hline $\begin{array}{l}\text { posterior reversible encephalopathy } \\
\text { syndrome }\end{array}$ & 0 & 0.0 & 1 & 6.7 & 0.309 \\
\hline
\end{tabular}

Table (2): Comparison between intervention and control groups in relation to serum Creatinine level on admission and on discharge, $(\mathrm{N}=30)$.

\begin{tabular}{|l|c|c|c|}
\hline \multirow{2}{*}{\multicolumn{1}{c|}{ Serum Creatinine level }} & $\begin{array}{c}\text { On admission } \\
(\mathbf{n = 1 5})\end{array}$ & $\begin{array}{c}\text { On discharge } \\
(\mathbf{n}=\mathbf{1 5})\end{array}$ & \multirow{2}{*}{ P-value } \\
\cline { 2 - 4 } & Mean \pm SD & Mean \pm SD & \\
\hline Intervention & $171.21 \pm 49.82$ & $98.11 \pm 35.95$ & $0.001 *$ \\
\hline Control & $188.42 \pm 48.79$ & $339.76 \pm 217.22$ & $0.011^{*}$ \\
\hline
\end{tabular}

Table (3): Comparison between intervention and control groups in relation to Fluid balance, $(\mathbf{N}=30)$.

\begin{tabular}{|c|c|c|c|}
\hline \multirow[t]{2}{*}{ Fluid balance } & $\begin{array}{c}\text { Intervention } \\
(n=15)\end{array}$ & $\begin{array}{c}\text { Control } \\
(n=15)\end{array}$ & \multirow[t]{2}{*}{ P-value } \\
\hline & Mean \pm SD & Mean \pm SD & \\
\hline \multicolumn{4}{|l|}{ On admission } \\
\hline Total intake/day & $7589.67 \pm 2769.62$ & $4796.67 \pm 2725.11$ & $0.006 *$ \\
\hline Total output/day & $4496.67 \pm 2420.04$ & $1846.67 \pm 1558.33$ & $0.001^{*}$ \\
\hline Fluid balance/day & $3093.00 \pm 3217.53$ & $2950.00 \pm 2718.46$ & 0.983 \\
\hline \multicolumn{4}{|l|}{ On mid period of ICU stay } \\
\hline Total intake/day & $7227.00 \pm 1865.07$ & $3057.14 \pm 2119.31$ & $0.000 *$ \\
\hline Total output/day & $5856.67 \pm 2485.45$ & $2792.14 \pm 1645.70$ & $0.001 *$ \\
\hline Fluid balance/day & $1370.33 \pm 2094.32$ & $265.00 \pm 2081.66$ & 0.183 \\
\hline \multicolumn{4}{|l|}{ On discharge } \\
\hline Total intake/day & $6163.67 \pm 2790.23$ & $3371.43 \pm 2170.67$ & $0.009 *$ \\
\hline Total output/day & $5743.33 \pm 2816.08$ & $2688.57 \pm 1853.64$ & $0.003 *$ \\
\hline Fluid balance/day & $420.33 \pm 1562.82$ & $682.86 \pm 1776.46$ & 0.678 \\
\hline
\end{tabular}


Table (4): Comparison between intervention and control groups in relation to water intake per day, $(\mathrm{N}=30)$.

\begin{tabular}{|l|c|c|c|}
\hline \multirow{2}{*}{ Oral fluid intake/day } & $\begin{array}{c}\text { Intervention } \\
(\mathbf{n = 1 5})\end{array}$ & $\begin{array}{c}\text { Control } \\
(\mathbf{n = 1 5})\end{array}$ & \multirow{2}{*}{ P-value } \\
\cline { 2 - 3 } & Mean \pm SD & Mean \pm SD & \\
\hline At admission & $2440.00 \pm 762.21$ & $776.67 \pm 777.79$ & $0.000^{*}$ \\
\hline At mid period of ICU stay & $5186.00 \pm 6931.81$ & $1396.67 \pm 942.16$ & $0.000^{*}$ \\
\hline At discharge & $3286.00 \pm 862.56$ & $1350.00 \pm 922.34$ & $0.000^{*}$ \\
\hline
\end{tabular}

Table (5): Comparison between intervention and control groups in relation to patients' outcomes, $(\mathbf{N}=30)$.

\begin{tabular}{|c|c|c|c|c|c|}
\hline \multirow[t]{2}{*}{ patients' outcomes } & \multicolumn{2}{|c|}{$\begin{array}{c}\text { Intervention } \\
(\mathbf{n}=\mathbf{1 5})\end{array}$} & \multicolumn{2}{|c|}{$\begin{array}{l}\text { Control } \\
(\mathrm{n}=15)\end{array}$} & \multirow[t]{2}{*}{ P-value } \\
\hline & No. & $\%$ & No. & $\%$ & \\
\hline \multicolumn{6}{|l|}{ 1-complications } \\
\hline Pulmonary edema & 0 & 0.0 & 2 & 13.3 & 0.483 \\
\hline Mechanical ventilation & 1 & 6.7 & 6 & 40.0 & 0.080 \\
\hline Early delivery & 5 & 33.3 & 5 & 33.3 & 1.000 \\
\hline Developing ARF & 0 & 0.0 & 9 & 60.0 & $0.001 *$ \\
\hline Developing CRF & 0 & 0.0 & 1 & 6.7 & 0.309 \\
\hline Uremic encephalopathy & 0 & 0.0 & 1 & 6.7 & 0.309 \\
\hline 2-Use of diuretics & 0 & 0 & 12 & 85.7 & $0.000 *$ \\
\hline 3-Use of hemodialysis & 0 & 0.0 & 3 & 21.4 & 0.100 \\
\hline 4-mortality rate & 0 & 0.0 & 5 & 33.3 & $0.042 *$ \\
\hline 5-ICU stay in days (Mean \pm SD) & \multicolumn{2}{|c|}{$4.07 \pm 2.02$} & \multicolumn{2}{|c|}{$5.33 \pm 3.62$} & 0.425 \\
\hline
\end{tabular}

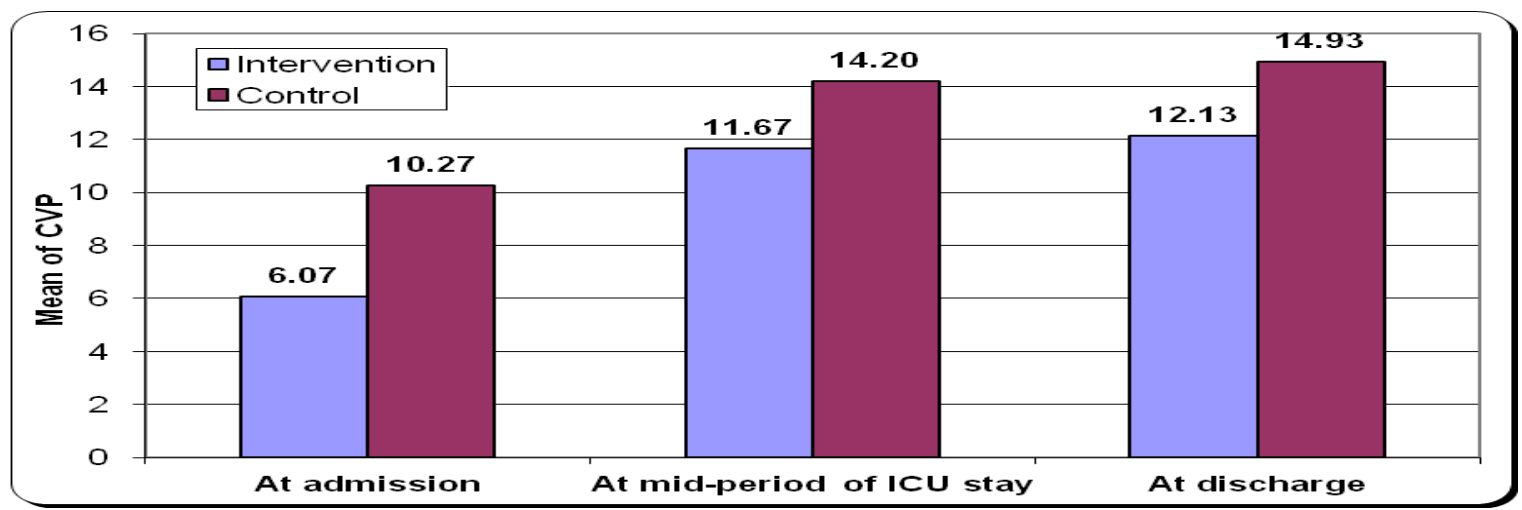

Figure (1): Comparison between the intervention and control groups in relation to central venous pressure, $(\mathbf{N}=30)$.

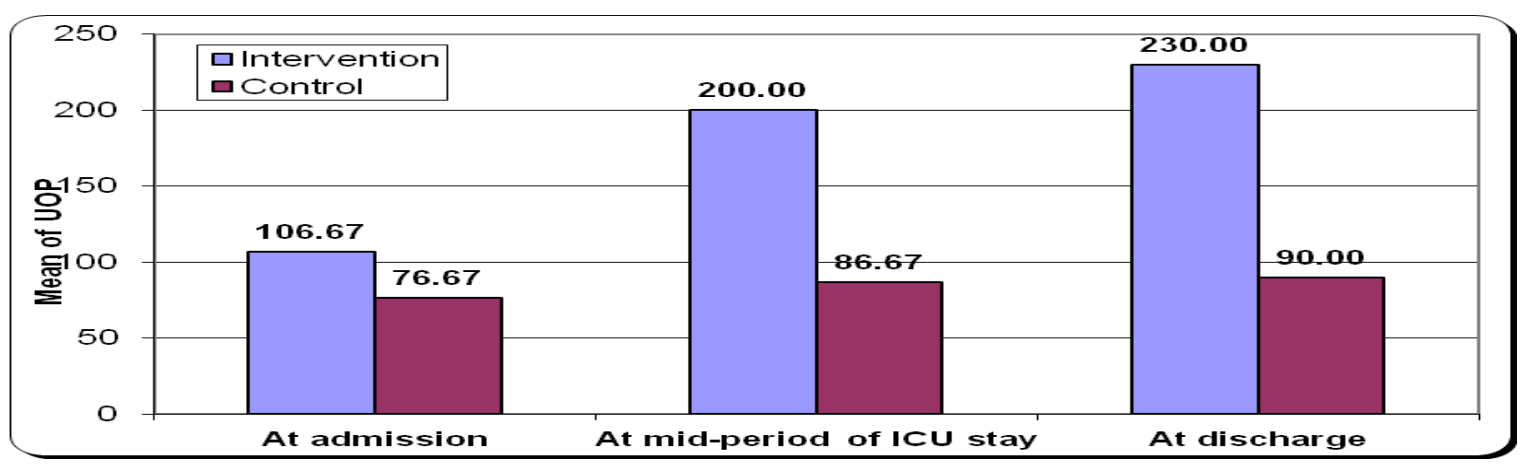

Figure (2): Comparison between the intervention and control groups in relation to urine output, $(\mathrm{N}=30)$. 


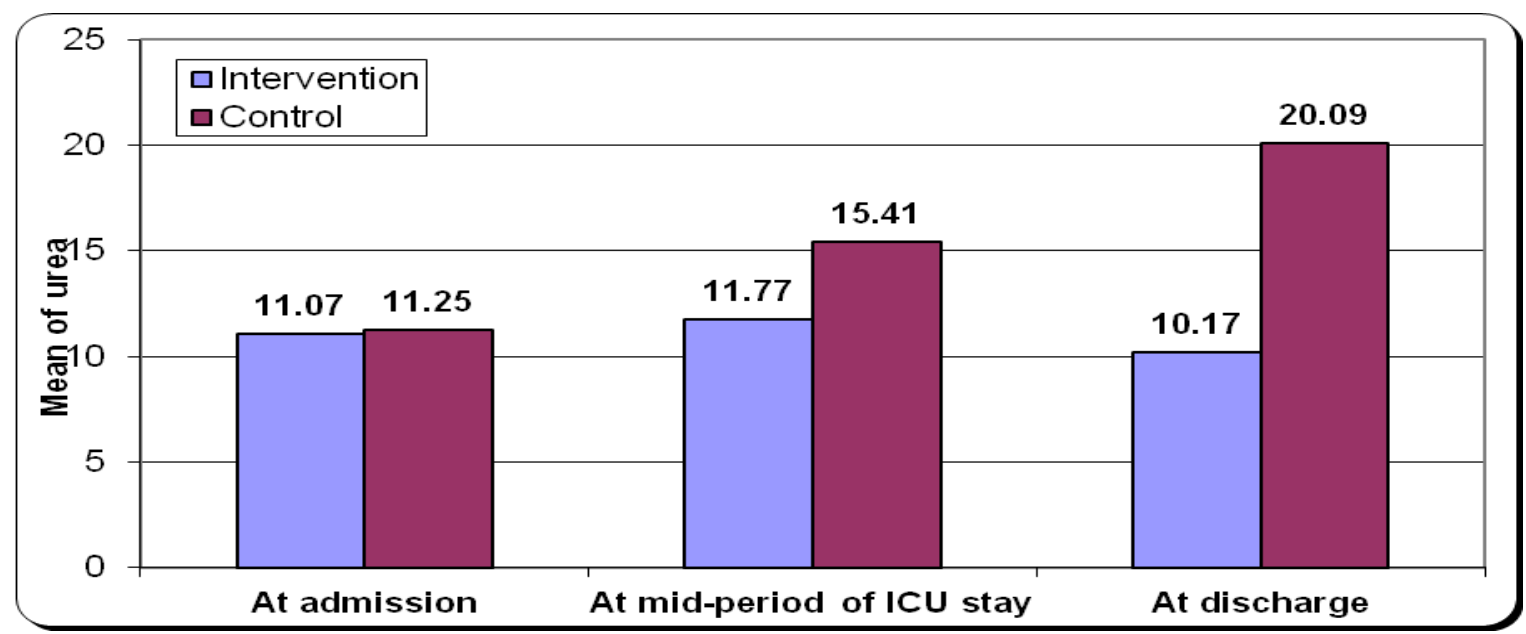

Figure (3): Comparison between the intervention and control groups in relation to serum urea level.

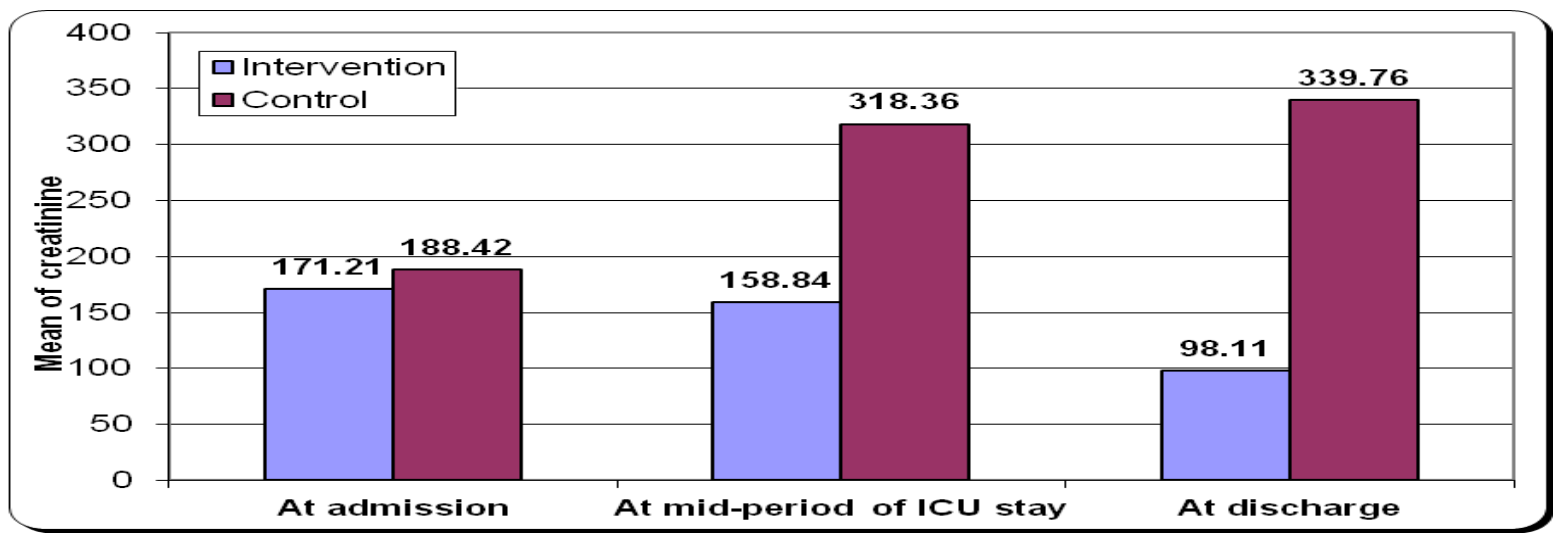

Figure (4): Comparison between the intervention and control groups in relation to serum Creatinine level.

Table (I): Illustrates personal characteristics and medical data of the intervention and control groups. Regarding to age, it was noticed that the mean age in intervention and control groups are nearly similar $(26.07 \pm 5.20 \& 28.47 \pm 5.18)$ respectively. As regard to type of delivery, the majority of the mothers in intervention group had cesarean section, but in the control group nearly half of patients had cesarean section (80\% and $46.7 \%)$ respectively. Regarding to the past history, the majority of mothers had no past history of disease in intervention and control groups (93.3\% and $86.7 \%$ ) respectively. As regard to the present illness, the majority of the mothers in intervention and control group complained from pregnancy induced hypertension and hemorrhage with its types $(60 \%, 40 \%, 33.3 \%$ and $33.3 \%)$ respectively. No significant statistical difference was put into evidence between the two studied groups in relation to age, type of delivery, past history and present illness.

Table (2): Shows that there was highly statistical significant difference in relation to serum Creatinine level in intervention group on admission and on discharge $(\mathrm{P}=0.001)$.

Table (3): Illustrates distribution of intervention and control groups in relation to fluid balance. It was noticed that there were statistical significant differences between intervention and control groups in relation to the total fluid intake per day on admission ,on mid period of ICU stay and on discharge $(\mathrm{P}=0.006 \& \mathrm{P}=0.000 \& \mathrm{P}=0.009)$ respectively. Regarding to the total output per day, it was found that there were highly statistical significant differences between intervention and control groups on admission, on mid period of ICU stay and on discharge $\quad(\mathrm{P}=0.001 \& \mathrm{P}=0.001 \& \mathrm{P}=0.003)$ respectively. No statistical significant differences were found between the two groups in relation to fluid balance ( $\mathrm{P}$ value $>0.05)$.

Table (4): Illustrates that there was a statistical significant difference between intervention and control groups regarding water intake per day at admission, at mid period of ICU stay and at discharge $(\mathrm{P}=0.000 \& \mathrm{P}=0.000 \& \mathrm{P}=0.000)$ respectively. 
Table (5): Illustrates patients' outcomes of the studied groups. Regarding complications, it was found that the majority of the control group developed ARF but no patients in the intervention group had developed ARF (60\% \& 0\%) respectively. There was a statistical significant difference between intervention and control groups in relation to developing ARF $(\mathrm{P}=0.001)$. Regarding to use of diuretics, it was found that $85.7 \%$ of patients in control group had received diuretics and no patients in the intervention group had received diuretics with presence of highly statistical significant differences between intervention and control groups in relation to use of diuretics $(\mathrm{P}=0.000)$. Regarding to use of hemodialysis, it was noticed that no patients in the intervention group had hemodialysis but $(21.4 \%)$ of patients in the control group had received hemodialysis. No statistical significant difference between intervention and control groups in relation to use of hemodialysis ( $\mathrm{P}$ value > 0.05). Regarding mortality rate, the results revealed that the mortality rate of the mother in the control group reached $33.3 \%$ but no deaths could be existed in the intervention group. There were statistical significant differences between intervention and control groups in relation to the mortality rate $(\mathrm{P}=0.042)$. Regarding to the length of ICU stay, it was noticed that the mean ICU stay in intervention and control groups $(4.07 \pm 2.02$ to $5.33 \pm$ 3.62) respectively. No statistical significant differences between intervention and control groups in relation to ICU stay ( $\mathrm{P}$ value $>0.05)$.

Figure (1): Shows that there were no statistical significant differences between the two studied groups in relation to CVP, as CVP in both groups remained in the normal range on mid period of ICU stay and on discharge.

Figure (2): Shows that urine output in the intervention group increased at mid period of ICU stay and still increased till discharge, but in the control group, urine output remained in the same amount from admission till discharge with significant statistical difference between the two groups in relation to urine output.

Figure (3): Shows that serum urea level increased all the period of ICU stay till discharge in the control group, but in the intervention group serum urea level began to increase on mid period of ICU stay and decreased on discharge.

Figure (4): Shows that serum Creatinine level in intervention group began to decrease in mid period of ICU stay and still decreasing at discharge till reaching to the normal range but the opposite had happened in control group.

\section{Discussion}

In the current study mean age in both groups are nearly similar with no statistically difference between intervention and control groups in relation to age, and this may be related to that this age is the reproductive age in Egypt.

In the current study, it was observed that patients with pregnancy induced hypertension (PIH), obstetric hemorrhage, acute fatty liver with pregnancy, were the high risk group for AKI in pregnancy, and it was observed that PIH as the most common cause contributing to AKI in less than two third of patients in intervention group and less than one third of patients in control group. Similar to this observation, study done by Hachim, (2001) who reported that preeclampsia and eclampsia in 41 of 55 (74.5\%) cases as main etiology of pregnancy related acute renal failure (PRARF).

In the current study, uterine hemorrhage was a significant cause of (PRAKI) as it was responsible for AKI in less than half of patients in intervention group and less than one third of patients in control group. Similar to this observation, uterine hemorrhage was the cause of PRAKI in the studies by Ansari, (2008) \& Naqvi, (1996) \& Alexopoulos, (1993) (38\% \& $58 \%$ \& $38 \%$ ) respectively.

In the current study, it was noticed that in the intervention, group urine output increased on mid period of ICU stay and still increased till discharge, but in control group, urine output remained in the same amount from admission till discharge with a significant statistical difference between the two groups in relation to urine output. This can be attributed to that fluid flow chart had a positive effect to maintain good urine output. This come in inferior of study done by young , (2015) who documented that no change in urine output in patients used normal saline $0.9 \%$ than the other who didn't use.

In the current study, it was found that serum Creatinine level in intervention group began to decrease in mid period of ICU stay and still decreasing at discharge till reaching to the normal range but the opposite had happened in control group which reflects that progress in patients followed fluid flow chart and maintaining daily body requirement of water (intervention group) are more better than patients who didn't receive this (control group).This is in line with study done by young, (2015) who noted changes in Creatinine level in patients used normal saline $0.9 \%$.

Oral fluid intake is well tolerated and effective in prevention and treatment of dehydration Ishikawa, (2010), Musekiwa \& Volmink, (2011). It can be used as preventive tool for PRAKI if maintain daily body requirements of water. In the current study, intervention group maintained adequate daily water 
intake which helped in optimizing good rehydration, and results showed that there was a statistical significant difference between intervention and control groups regarding water intake per day on admission, on mid period of ICU stay and on discharge.

In the current study, it was found that less than two third of patients in control group developed ARF but no patients in the intervention group had developed ARF or any other complication with a statistical significant difference between intervention and control groups in relation to developing ARF, moreover, it was found that the majority of patients in control group had received diuretics and no patients in the intervention group had received diuretics with presence of statistical significant differences between intervention and control groups in relation to use of diuretics. Furthermore, it was noticed that no patients in the intervention group had hemodialysis but less than one third of patients in the control group had received hemodialysis, and it was found that the mortality rate of the mother in the control group reached five that representing less than one third of them, but no deaths could be existed in the intervention group, but should put in mind that not all of the deaths in the control group be as a result from AKI as there are contributing factors like acute fatty liver with pregnancy which was fatal and had bad prognosis. This may be attributed that close follow up of urine output and CVP and administering or restricted fluids according to them helped more in preventing complications in intervention group.

\section{Conclusions}

Based on the results of this study, it could be concluded that: implementing standardized nursing care by using fluid therapy with normal saline $0.9 \%$ and applying protocol of fluid flow chart and maintaining daily body requirement of water were significantly effective in preventing developing AKI among at risk pregnant and post partum women.

\section{Recommendations}

The following recommendations are suggested:-

- Emphasize on the importance of applying fluid therapy protocol in the obstetric intensive care unit and its importance in preventing complications for patients who at risk for developing AKI.

- Emphasize on the importance of accurate monitoring of urine output and CVP in obstetric patients who at risk for developing AKI in detection and preventing any problem or deterioration.
- Fluid volume status should be carefully assessed with respect to both fluid depletion and fluid overload.

- The nurse should assess serum Creatinine level daily to follow the trend of kidney functions and to determine whether it is stable, getting better or getting worse and comparing it with the base line of the patient and escalating the case to the medical staff if there are raising serum Creatinine.

- Emphasize on the importance of providing adequate hydration, in particular for patients who rely on others to provide drinks.

- Replicate this research on a larger probability sample acquired from different geographical areas in Egypt for generalization

\section{References}

1. Alexopoulos E., Tambakoudis P., \& Bili H., (1993): Acute renal failure in pregnancy, 15, pp. (609-613).

2. Ansari M., Laghari M., Solangi K., (2008): Acute renal failure in pregnancy: One year observational study at Liaquat University Hospital, Hyderabad. J Pak Med Assoc.; 58, pp. (61-64).

3. Anthony M., \& Michael F., (2009): colloids and crystalloids; does it matter to the kidney? Current opinion in critical care 15:520-524.

4. Baylis, C., \& John M., Davidson (2007): Renal Physiology in normal pregnancy, In Comprehensive Clinical Nephrology: $3^{\text {rd }}$ ed edited by John Feehally, Jurgen Floege, Richard J. Johnson. Mosby Elsevier, pp. (475-504).

5. Bouchard J., Soroko S., \& Chertow G., (2009): Fluid accumulation, survival and recovery of kidney function in critically ill patients with acute kidney injury. Kidney Int., 76, pp. (422-427).Doi: 10.1038/ki.2009.159. [PubMed] [Cross Ref]

6. Brodovicz, K., Uemura, N., \& Yale S., (2009): Reliability and feasibility of methods to quantitatively assess peripheral edema. Clinical Medicine \& Research, 7(1/2) P 21-31. Available at: http://www.EBSCOhost.com.

7. Cheung C., Ponnusamy, A., \& Anderton J., (2008): Management of acute renal failure in the elderly patient: A clinician's guide. Drugs \&Aging, 25(6), pp. (455-476).

8. Davenport A., \& Stevens P., (2008): Clinical practice guidelines; acute kidney injury, ch.5, $1^{\text {st }}$ ed. Available at: WWW. Renal .org/guidelines.

9. Hachim K., Badahi K., \& Benghanem M., (2001): Obstetrical acute renal failure. Experience of the nephrology department, Central University Hospital ibn Rochd, Casablanca. Nephrologie, 22, pp. (29-31). 
10. Ishikawa T., Tamura H., \& Ishiguro H., (2010): Effect of oral rehydration solution on fatigue during outdoor work in a hot environment: a randomized crossover study. J Occup Health, 52(4), pp. (209-15). Doi: 10.1539/joh.L9156. [PubMed] [Cross Ref]

11. John W., (2012): Acute kidney injury; a guide to clinical practice, $1^{\text {st }}$ ed., Imprenta Tomas Hermanos Rio Manzanares, 42-44 • E28970 Humanes de Madrid, Madrid - Spain, pag.(16).

12. Kao S., (2015): Variability in inpatient serum Creatinine: its impact upon short- and long-term mortality. QJM. 2015; pii: hcv020. [Epub ahead of print].

13. Lindheimer M., Taler S., \& Cunningham F., (2010): Hypertension in pregnancy. J Am Soc Hypertens, 4(2):68-78. [Medline]

14. Musekiwa A., \& Volmink J., (2011): Oral rehydration salt solution for treating cholera: $</=$ $270 \mathrm{mOsm} / \mathrm{L}$ solutions vs $>/=310 \mathrm{mOsm} / \mathrm{L}$ solutions. Cochrane Database Syst Rev. 2011; 12:CD003754. [PubMed]

15. Naqvi R., Akhtar F., and Ahmed E., (1996): Acute renal failure of obstetrical origin during 1994 at one centre. Ren Fail 1996; 18, pp.(681683

16. Navadiya N., Ninama P., \&Vohra H., (2016): Postpartum acute kidney injury; Falling trend in Developing world ,SCI. Journal , vol.8(21),pp.(36-37).

17. Praught M., \& Shlipak M., (2005): Are small changes in serum creatinine an important risk factor? Curr Opin Nephrol Hypertens 2005; 14, pp. (265-270).

18. Rani P., \& Narayen G., (2002): Changing trends in pregnancy related acute renal failure. $\mathrm{J}$ Obstet Gynecol India 2002; 52: 36-8.

19. Remond A., Mcdevitt M., \& Barnes S., (2004): Acute renal failure: recognition and treatment in ward patients. Nursing standard Royal College of Nursing, 2004, 18(22) ,pp.(46-53).

20. South Australian perinatal practice guidelines work group, (2001): available at: cywhs.perinatalprotocol@health.sa.gov.au

21. Steddon S., Ashman N., \& Chesser A., (2006): Oxford handbook of nephrology and hypertension. London:Oxford University Press; 2006.

22. Talbot, S., (2008): Acute renal failure. In P. Jevon, B. Ewens, \& M. Humphreys (Eds.), Nursing medical emergency patients, pp. (199229).

23. Westacott R., (2009): Management of acute renal injury,university ospitals of Leicester NHS trust ,version (1),No.B21/2009,pp.(1-16).
24. Yaklin, K., (2011): Acute kidney injury: An overview of pathophysiology and treatments. Nephrology Nursing Journal, 38(1), 13-19, 30

25. Young P., Bailey M., \& Beasley R., (2015): Effect of a Buffered Crystalloid Solution vs Saline on Acute Kidney Injury among Patients in the Intensive Care Unit: The SPLIT Randomized Clinical Trial. Jama. 2015; 314(16), pp. (17011710). 